\title{
Physical activity in children with type 1 diabetes
}

\author{
Cristiane P. Miculis, ${ }^{1}$ Luis P. Mascarenhas, ${ }^{2}$ \\ Margaret C. S. Boguszewski, ${ }^{3}$ Wagner de Campos ${ }^{4}$
}

\begin{abstract}
Objectives: To discuss the practical aspects of safe physical activity and sports participation in children and adolescents with type 1 diabetes mellitus.

Sources: A literature search was conducted using national (SciELO) and international (PubMed/MEDLINE) databases and the reference lists of the articles found, adopting the following limits: articles on physical activity published in the last 10 years, preferably conducted in children and adolescents with type 1 diabetes. Most studies had an experimental design or were meta-analyses.

Summary of the findings: Skeletal muscle glucose uptake is greater during aerobic metabolism in order to generate energy for muscle contraction, which suppresses hepatic gluconeogenesis and thus promotes a decrease in blood glucose levels and increased risk of hypoglycemia. Adequate carbohydrate replacement before, during, and after exercise and reduction of preprandial rapid-acting insulin doses are the main allies in avoiding severe hypoglycemic events among diabetic children and adolescents.

Conclusions: Type, duration, and intensity of physical activity must be considered when planning carbohydrate replacement and insulin dose reduction, as must the timing of exercise. Nonetheless, physical activity and participation in many individual and team sports is possible and highly recommended in the treatment of type 1 diabetes in children and adolescents.
\end{abstract}

J Pediatr (Rio J). 2010;86(4):271-278: Type 1 diabetes mellitus, exercise, hypoglycemia, children, adolescents.

\section{Introduction}

Type 1 diabetes (T1D) is an autoimmune disease characterized by progressive loss of pancreatic beta cells, culminating in the cessation of insulin production and, consequently, a severe metabolic imbalance.1,2 It is estimated that only 10 to $20 \%$ of beta cells are usually functional at the time of diagnosis. ${ }^{3}$

The prevalence of T1D has been increasing considerably throughout the world; it is highest in the Nordic countries and very low in Asia. ${ }^{4}$ For Brazil, no national data on the incidence or prevalence of T1D are available, but according to regional studies, the incidence ranges from 7.6 to 12 cases per 100,000 person-years. ${ }^{5-7}$

The microvascular and macrovascular complications of diabetes are usually found in patients with T1D of 15 to 20 years' duration, 8 and are uncommon before the age of $10 .{ }^{9}$ However, microvascular disease, such as diabetic retinopathy and nephropathy, is highly influenced by glycemic control and may be found in adolescents with T1D.10,11

1. Mestre, Educação Física, Departamento de Educação Física, Universidade Federal do Paraná (UFPR), Curitiba, PR, Brazil.

2. Doutorando, Saúde da Criança, Departamento de Pediatria, UFPR, Curitiba, PR, Brazil.

3. Doutora. Professora associada, Departamento de Pediatria, Unidade de Endocrinologia Pediátrica, UFPR, Curitiba, PR, Brazil.

4. Doutor. Professor titular, Departamento de Educação Física, UFPR, Curitiba, PR, Brazil.

This study was conducted at Universidade Federal do Paraná (UFPR), Curitiba, PR, Brazil.

No conflicts of interest declared concerning the publication of this article.

Suggested citation: Miculis CP, Mascarenhas LP, Boguszewski MC, de Campos W. Physical activity in children with type 1 diabetes. J Pediatr (Rio J). 2010;86(4):271-278.

Manuscript submitted Jan 21 2010, accepted for publication Feb 242010.

doi:10.2223/JPED.2003 
On the other hand, cardiovascular disease (CVD) tends to occur mainly in adulthood, ${ }^{12}$ and the prevention of these comorbidities may be the greatest benefit derived from regular physical activity (PA).

The influence of PA on the glycated hemoglobin levels (HbA1c) of children with T1D appears to favor improved glycemic control; most studies have found significant decreases in $\mathrm{HbA} 1 \mathrm{c}$ levels after completion of a regular physical activity program. ${ }^{13,14}$ Furthermore, experimental studies confirm significant improvement in lipid profile, blood pressure, and body composition (all of which are classic risk factors for CVD) in children and adolescents with T1D. ${ }^{15,16}$

The proven preventive action of PA (whether recreational or competitive ${ }^{14,17-20}$ ) notwithstanding, levels of physical activity are lower than recommended in most children and adolescents with T1D, ${ }^{21-23}$ which further increases the risk of early-onset microvascular and macrovascular disease.

This review sought to address the practical aspects of safe physical activity and sports participation in children and adolescents with T1D, as well as the role of hypoglycemia as a barrier to an active lifestyle and which activities and sports are most indicated in this population.

\section{Why exercise?}

Children and adolescents with T1D are at greater risk of developing microvascular complications (diabetic retinopathy, nephropathy, and neuropathy) 10,24 and cardiovascular disease. ${ }^{12,25}$ Recent studies show that signs of atherosclerotic disease, 26,27 diabetic retinopathy, and diabetic nephropathy are already detectable in early childhood. ${ }^{24}$

The main risk factors for development of the aforementioned conditions are lack of adequate glycemic control $^{10}$ (Table 1), dyslipidemia, obesity, high blood pressure, and physical inactivity. ${ }^{28-32}$ All of these factors may be prevented by adhering to a balanced diet that is appropriate for children and adolescents with T1D, strict compliance with insulin administration and fingerstick glucose monitoring, and maintaining an active lifestyle. ${ }^{10,33}$
In spite of the health benefits of engaging in 30 to 60 minutes of moderate to vigorous physical activity on a regular basis, 34,35 most youths do not follow this recommendation. ${ }^{31,36}$ Considering that PA levels and cardiorespiratory fitness tend to decrease with age, 37,38 encouraging and providing opportunities for engaging in PA since childhood may foster the maintenance of an active lifestyle into adulthood, ${ }^{39}$ and may also improve fasting blood glucose levels and insulin sensitivity, particularly in children and adolescents with T1D. 16,40,41

Aerobic PA uses muscle and liver glycogen, blood glucose, and free fatty acids as its main energy sources, depending on the duration and intensity of activity. ${ }^{42}$ In order to achieve the aforementioned health benefits, the literature recommends moderate to vigorous $[40-85 \%$ of maximal oxygen consumption $\left(\mathrm{VO}_{2} \mathrm{max}\right)$ or $55-90 \%$ of maximum heart rate (HRmax)], three to five times a week, for 20 to 60 minutes, ${ }^{43}$ with 5 to 10 minutes of low-intensity aerobic activity as a warm up and 5 to 10 minutes of stretching after each activity; strength training exercises may also be added at least twice a week. ${ }^{34}$

\section{The fear of hypoglycemia}

One of the main issues complicating PA in children with T1D is the frequent occurrence of hypoglycemia during or even hours after exercise, 44,45 which ultimately discourages these children from engaging in regular PA. 44

Hypoglycemia may be due to excessive administration of exogenous insulin prior to aerobic exercise, inadequate insulin:glucagon ratio, or increased insulin sensitivity. 45 During aerobic metabolism, skeletal muscle glucose uptake increases to permit the generation of energy, thus decreasing hepatic gluconeogenesis ${ }^{46}$ and lowering blood glucose levels.

Insulin-dependent diabetics have no physiological parameters to inhibit insulin action; their sensitivity to the effects of exogenous insulin remains constant during physical exercise. ${ }^{45}$ Conversely, in nondiabetic individuals, exercise is accompanied by a suppression in the production and release of insulin by the pancreas, stimulating hepatic

Table 1 - Optimal glycemic control by age range

\begin{tabular}{lccc}
\hline & \multicolumn{3}{c}{ Plasma blood glucose $\mathbf{( m g / d L )}$} \\
\cline { 2 - 4 } Age & Preprandial & Postprandial & HbA1c \\
\hline 0-6 years & $100-180$ & $110-200$ & $<8.5$ and $>7.5 \%$ \\
6-12 years & $90-180$ & $100-180$ & $<8 \%$ \\
$13-19$ years & $90-130$ & $90-150$ & $<7.5 \%$ \\
\hline
\end{tabular}

$\mathrm{HbA} 1 \mathrm{c}=$ glycated hemoglobin .

Source: American Diabetes Association (ADA) ${ }^{33}$ 
glucose release by increasing glucagon levels and thus stabilizing plasma glucose levels. 46

Despite the risk of hypoglycemia, PA is recommended in children with T1D. 47,48 According to Hoffman, 49 with an adequate insulin regimen and a personalized diet, children with T1D may enjoy all the physical and psychosocial benefits derived from exercise.

After defining the type, intensity, and duration of the intended $\mathrm{PA}$, one must reduce the preprandial insulin dosage by 25 to $75 \% 50$ and provide adequate simple carbohydrate replacement. ${ }^{51}$ Nonetheless, an episode of hypoglycemia may occur even when these precautions are observed. ${ }^{1}$ The following procedure is then recommended 49 : blood glucose levels should be measured at the first symptoms of hypoglycemia (i.e., weakness, dizziness, tremor, drowsiness, diaphoresis, hunger, confusion, combativeness). If measurement confirms hypoglycemia, provide $15 \mathrm{~g}$ of a simple carbohydrate, wait 15 minutes and repeat blood glucose measurement. If blood glucose levels are still below normal range, repeat carbohydrate as necessary. When the child is unable to ingest carbohydrates, however, 1 mg glucagon should be given by intramuscular injection as an emergency measure. 52

The effects of PA on cardiovascular and metabolic risk factors certainly outweigh the adverseness of possible hypoglycemic events. ${ }^{13,15}$ Herbst et al. ${ }^{47}$ reported that regular PA is the single factor that has the greatest influence on glycemic control without increasing the risk of hypoglycemia in children with T1D. Some studies have indeed proven that regular PA, whether continuous or intermittent, ${ }^{41}$ does not increase the risk of hypoglycemia in children and adolescents. ${ }^{13}$

\section{Avoiding hypoglycemia during physical activity}

The litersture describes two factors as being essential for the prevention of hypoglycemia during PA in children and adolescents. These factors are discussed below.

\section{Carbohydrate replacement}

The first precaution before any physical activity should involve carbohydrate ( $\mathrm{CHO}$ ) replacement, on the basis of pre-exercise blood glucose levels (Table 2), which may signal that exercise should be postponed or even contraindicated. 53-55

When PA is not programmed, $\mathrm{CHO}$ replacement is the main precaution in avoiding a hypoglycemic episode. ${ }^{51}$ However, replacement should be just enough to avoid the occurrence of hypoglycemia, as excessive $\mathrm{CHO}$ intake may lead to weight gain, which is undesirable and would negate the benefits of exercise. ${ }^{10,57}$ Furthermore, the amount of $\mathrm{CHO}$ ingested varies according to the duration and intensity of PA. ${ }^{51}$

For light physical activity ( $<50 \% \mathrm{VO}_{2}$ max) of 30 to 60 minutes' duration, $\mathrm{CHO}$ replacement should be determined by pre- and post-exercise blood glucose levels. In moderate (50-75\% $\mathrm{VO}_{2} \mathrm{max}$ ) or vigorous ( $75 \% \mathrm{VO}_{2} \mathrm{max}$ ) activity lasting 60 minutes or longer, $\mathrm{CHO}$ replacement may be required before, during, and after the activity. In this case, replacement should follow the formula of 1 to $1.5 \mathrm{~g}$ of $\mathrm{CHO}$ per $\mathrm{kg}$ body weight per hour of activity. Blood glucose levels should always be measured before a carbohydrate is offered. 54,55

\section{Insulin dose reduction}

Any changes in insulin dose should be approached cautiously and follow physician recommendations, as many contradictions surround insulin dose reductions, and there is no national or international consensus on the matter. ${ }^{58}$ However, most researchers recommend a personalized dose reduction on the basis of exercise intensity, duration, and timing, as well as the type of insulin administered prior to activity. ${ }^{55}$

Reductions in regular insulin dose are warranted when exercise occurs 2 to 3 hours after insulin administration.

Table 2 - Pre-exercise carbohydrate replacement

\begin{tabular}{ll}
\hline Plasma blood glucose & Simple carbohydrate (CHO) \\
\hline$<80 \mathrm{mg} / \mathrm{dL}$ & $\begin{array}{l}\text { Withhold physical activity + ingest } 15 \mathrm{~g} \mathrm{CHO} \\
\text { (cereal bar, fruit, honey sachets, etc.). }\end{array}$ \\
80 to $140 \mathrm{mg} / \mathrm{dL}$ & Ingest 1 to $2 \mathrm{~g} / \mathrm{kg}$ of CHO prior to activity. \\
$>140 \mathrm{mg} / \mathrm{dL}<250 \mathrm{mg} / \mathrm{dL}$ & Within safety range; ingest 15 to $30 \mathrm{~g}$ CHO after activity. \\
$>300 \mathrm{mg} / \mathrm{dL}$, no ketonuria & Begin activity. No CHO replacement necessary. \\
$>300 \mathrm{mg} / \mathrm{dL}$, with ketonuria & Postpone activity until ketone levels return to normal. \\
& Take fluids (water). No CHO replacement necessary.
\end{tabular}

$\mathrm{CHO}=$ simple carbohydrate.

Source: Adapted from the Brazilian Diabetes Society (Sociedade Brasileira de Diabetes, SBD). ${ }^{56}$ 
Table 3 - Adjustment of preprandial (rapid-acting) insulin dose according to the intensity of physical activity

\begin{tabular}{lcc}
\hline & \multicolumn{2}{c}{ Percentage reduction in insulin dose } \\
\cline { 2 - 3 } Exercise intensity $\left(\% \mathbf{V O}_{\mathbf{2}} \mathbf{m a x}\right)$ & $\mathbf{3 0}$ min exercise & $\mathbf{6 0}$ min exercise \\
\hline 25 & $25 \%$ & $50 \%$ \\
50 & $50 \%$ & $75 \%$ \\
75 & $75 \%$ & - \\
\hline
\end{tabular}

$\% \mathrm{VO}_{2} \max =$ percentage of maximal oxygen consumption. Source: Rabasa-Lhoret et al. ${ }^{50}$

Conversely, a reduction in preprandial rapid-acting insulin should be prioritized when exercise occurs within 1 hour of administration. When PA occurs in the late afternoon or evening, the dose of rapid-acting insulin administered before the evening meal should be reduced instead. $48,55,59$

The Brazilian Diabetes Society (Sociedade Brasileira de Diabetes, SBD) ${ }^{56}$ advises a reduction in insulin dose according to the intensity and duration of physical exercise, based on the data reported by Rabasa-Lhoret et al. ${ }^{50}$ (refer to Table 3).

\section{Blood glucose changes during exercise}

Changes in blood glucose during physical exercise vary according to the type and intensity of activity; therefore, we will discuss the effects of both aerobic and anaerobic exercise.

\section{Continuous moderate physical activity}

Continuous moderate PA is effective in reducing blood glucose in patients with T1D, as it increases skeletal muscle glucose uptake. ${ }^{45}$ In individuals with T1D, the physiological mechanisms of glucose counterregulation are altered. 45,60 In non-diabetics, the drop in blood glucose that follows the onset of physical activity inhibits pancreatic insulin secretion, increasing hepatic glucose production and thus balancing glucose uptake and output. ${ }^{54}$ In patients with T1D, as endogenous insulin production is absent, the body is unable to control its availability, increasing the risk of hypoglycemia. 60

Furthermore, aerobic exercise increases insulin sensitivity, exacerbating the action of insulin when it is administered prior to PA. ${ }^{61}$ Hence, compliance with $\mathrm{CHO}$ replacement and insulin dose reduction recommendations must be particularly strict during aerobic exercise. ${ }^{62}$

\section{Continuous vigorous physical activity}

In high-intensity exercise, hypoglycemic episodes are less common than in light-to-moderate continuous activity, 41 as the non-insulin-independent mechanisms of glucose regulation are preserved in people with T1D. Therefore, during vigorous activity, hepatic glucose production will be controlled by catecholamine release. ${ }^{54}$

In addition to modulating endocrine functions such as insulin secretion and rate of glycogenolysis, catecholamines (epinephrine, norepinephrine, dopamine) have excitatory and inhibitory effects on the peripheral nervous system, and act on the central nervous system (CNS) as well. ${ }^{63}$

In vigorous exercise, the main concern is not postexercise hypoglycemia, but rather hypoglycemia, as the insulin-mediated regulatory mechanisms are absent. Therefore, extra carbohydrate replacement or insulin dose reduction may exacerbate post-high-intensity exercise hyperglycemia. ${ }^{54}$ Should vigorous exercise be the activity of choice for a child or adolescent, insulin administration immediately after conclusion of the activity may be necessary. 64

\section{Intermittent, moderate to vigorous physical activity}

Recent studies suggest this is the ideal type of exercise for children and adolescents with T1D.41,65-67 In addition to mimicking most of the common activities of childhood, 
such as football, volleyball, tag, etc., this type of exercise appears to have a balancing effect on blood glucose during and after the activity, reducing the rate of hypoglycemic events (moderate PA) without exacerbating hypoglycemia (high-intensity PA) ${ }^{54}$.

Intermittent vigorous exercise produces a less pronounced decline in blood glucose, as it stimulates hormonal and metabolic responses antagonistic to blood glucose reduction. This type of PA raises serum lactate levels, which may contribute to a lesser reduction in blood glucose by antagonizing the action of insulin (whether endogenous or exogenous) on peripheral glucose reuptake ${ }^{68}$ and stimulating glucose production by hepatic gluconeogenesis. 69

Furthermore, the catecholamine spike that occurs in response to intermittent vigorous exercise stimulates hepatic glucose production and simultaneously inhibits insulin-mediated glucose uptake. ${ }^{70}$

\section{Resistance training}

Not only is aerobic PA indicated in children and adolescents with $T 1 D$, but engaging in resistance training two or three times a week is also recommended 33,35 with the objectives of maintaining or increasing muscle strength, increasing energy expenditure, reducing visceral fat, and improving bone density. ${ }^{54}$

According to Andersen, ${ }^{71}$ resistance exercises may be an alternative for the training of T1D patients and diabetic patients with lower extremity microvascular complications (such as peripheral neuropathy and diabetic foot) who are unable to engage in high-impact exercise.

However, there are no specific recommendations on insulin dose reduction and/or $\mathrm{CHO}$ replacement for this type of activity, nor is there information available on its effects in people with T1D. 40 Mosher et al. ${ }^{14}$ showed that resistance training combined with aerobic exercise improved cardiorespiratory fitness, muscle strength, lipid profile, and glycemic control in children with T1D. Furthermore, only one participant in their study developed hypoglycemia. On the other hand, Ramalho et al. ${ }^{72}$ found no effect of resistance training on lipid profile or glycemic control.

\section{Sports and the child with type 1 diabetes}

The countless benefits of regular physical exercise outweigh the risk of hypoglycemia occurring during physical activity. ${ }^{13,15}$ The rate of hypoglycemic episodes is considerably reduced when guidance on insulin dose reduction, $\mathrm{CHO}$ replacement, and type of activity engaged in are followed. 49

Herbst et al. ${ }^{47}$ report that regular PA is the single factor that most influences glycemic control without increasing the risk of hypoglycemia in children with T1D. Indeed, some studies have shown that regular PA, whether continuous or intermittent, $41,66,73$ does not increase the risk of hypoglycemia. 13

Were one to follow this line of reasoning, the most indicated types of PA would be those which feature a progressive increase in effort over a prolonged period of physical stimulation. ${ }^{74}$ Several team sports (football, volleyball, basketball, handball, swimming, lawn tennis) and individual sports - including martial arts (judo, jujitsu), surfing, track, walking, and cycling - thus meet recommendations for physical activity in children and adolescents with diabetes. ${ }^{23,75}$ The choice of PA should depend on individual ability, goals of exercise, and, most importantly, enjoyment.

The chosen activity or sport should also be ageappropriate; sports in early childhood should thus have as their main objectives playing, taking short walks, running, jumping, swimming, turning cartwheels, etc. Between the ages of 6 and 9, competitive activities with flexible rules may be introduced, as may sports such as gymnastics, competitive swimming, cycling, skateboarding, and team sports. From the ages of 10 or 12, sports such as football, swimming, tennis, volleyball, artistic gymnastics, dancing, and water sports may be introduced with a specific focus on competition and the acquisition and betterment of individual abilities. ${ }^{76}$ In some sports, however, such as auto racing, parachuting, rock and mountain climbing, and diving, measurement and correction of blood glucose levels is more difficult and less reliable; these activities are therefore discouraged. 57

\section{Conclusion}

It must be stressed that moderate aerobic exercise interspersed with periods of high-intensity physical activity is effective in reducing the rate of hypoglycemia, and that sports participation is safe for children and adolescents with type 1 diabetes. However, caution is indicated in following current guidelines on rapid-acting insulin dose reduction, in light of the different types of insulin available on the market. Furthermore, as few randomized, double-blind, controlled trials have been conducted in the pediatric population, insulin dose adjustments must be personalized and discussed with the patient's endocrinologist.

Encouraging T1D patients to take part in recreational or competitive sports, whether individually or as part of a team, plays an essential role in controlling metabolic and lipid profiles and blood pressure, as well as other factors such as well-being, self-esteem, and self-confidence. This may help reduce the morbidity and mortality associated with the complications of diabetes and, concomitantly, improve quality of life in pediatric T1D patients. 


\section{References}

1. Silink M. Childhood diabetes: a global perspective. Horm Res. 2002;57 Suppl 1:1-5.

2. Fernandes $A P$, Pace $A E$, Zanetti ML, Foss MC, Donadi EA. Fatores imunogenéticos associados ao diabetes mellitus do tipo 1 . Rev Lat Am Enfermagem. 2005;13:743-9.

3. Knip M, Veijola R, Virtanen SM, Hyöty H, Vaarala O, Åkerblom HK. Environmental triggers and determinants of type 1 diabetes. Diabetes. 2005;54 Suppl 2:S125-36.

4. Karvonen M, Viik-Kajander M, Moltchanova E, Libman I, LaPorte R, Tuomilehto J. Incidence of childhood type 1 diabetes worldwide. Diabetes Mondiale (DiaMond) Project Group. Diabetes Care. 2000;23:1516-26.

5. Ferreira SR, Franco LJ, Vivolo MA, Negrato CA, Simoes AC, Ventureli CR. Population-based incidence of IDDM in the state of São Paulo, Brazil. Diabetes Care. 1993;16:701-4.

6. Lisbôa HR, Graebin R, Butzke L, Rodrigues CS. Incidence of type 1 diabetes mellitus in Passo Fundo, RS, Brazil. Braz J Med Biol Res. 1998;31:1553-6.

7. Negrato CA, Dias JP, Teixeira MF, Dias A, Salgado MH, Lauris JR, et al. Temporal trends in incidence of type 1 diabetes between 1986 and 2006 in Brazil. J Endocrinol Invest. 2009. [ahead of print]

8. Effect of intensive diabetes treatment on carotid artery wall thickness in the epidemiology of diabetes interventions and complications. Epidemiology of Diabetes Interventions and Complications (EDIC) Research Group. Diabetes. 1999;48:383-90.

9. Asmal AC, Dayal B, Jialal I, Leary WP, Omar MA, Pillay NL, et al. Non-insulin-dependent diabetes mellitus with early onset in Blacks and Indians. S Afr Med J. 1981;60:93-6.

10. The effect of intensive treatment of diabetes on the development and progression of long-term complications in insulin-dependent diabetes mellitus. The Diabetes Control And Complications Trial Research Group. N Engl J Med. 1993;329:977-86.

11. The absence of a glycemic threshold for the development of longterm complications: the perspective of the Diabetes Control and Complications Trial. Diabetes. 1996;45:1289-98.

12. Skrivarhaug T, Bangstad HJ, Stene LC, Sandvik L, Hanssen $\mathrm{KF}$, Joner G. Long-term mortality in a nationwide cohort of childhood-onset type 1 diabetic patients in Norway. Diabetologia. 2006;49:298-305.

13. Bernardini AL, Vanelli M, Chiari G, Iovane B, Gelmetti C, Vitale R, et al. Adherence to physical activity in young people with type 1 diabetes. Acta Biomed. 2004;75:153-7.

14. Mosher PE, Nash MS, Perry AC, LaPerriere AR, Goldberg RB. Aerobic circuit exercise training: effect on adolescents with wellcontrolled insulin-dependent diabetes mellitus. Arch Phys Med Rehabil. 1998;79:652-7.

15. Khawali C, Andriolo A, Ferreira SR. Benefícios da atividade física no perfil lipídico de pacientes com diabetes tipo 1. Arq Bras Endocrinol Metab. 2003;47:49-54.

16. Lehmann R, Kaplan V, Bingisser R, Bloch KE, Spinas GA. Impact of physical activity on cardiovascular risk factors in IDDM. Diabetes Care. 1997;20:1603-11.

17. Heyman E, Toutain C, Delamarche P, Berthon P, Briard D, Youssef $\mathrm{H}$, et al. Exercise training and cardiovascular risk factors in type 1 diabetic adolescent girls. Pediatr Exerc Sci. 2007;19:408-19.

18. Laaksonen DE, Atalay M, Niskanen LK, Mustonen J, Sen CK, Lakka TA, et al. Aerobic exercise and the lipid profile in type I diabetic men: a randomized controlled trial. Med Sci Sports Exerc. 2000;32:1541-8.

19. Rigla M, Sánchez-Quesada JL, Ordóñez-Llanos J, Prat T, Caixàs A, Jorba $O$, et al. Effect of physical exercise on lipoprotein(a) and low-density lipoprotein modifications in type 1 and type 2 diabetic patients. Metabolism. 2000;49:640-7.
20. Sideravičiūtè $S$, Gailiūniene A, Visagurskiene $K$, Vizbaraite D. The effect of long-term swimming program on body composition, aerobic capacity and blood lipids in 14-19-year aged healthy girls and girls with type 1 diabetes mellitus. Medicina (Kaunas). 2006;42:661-6.

21. Herbst A, Kordonouri O, Schwab KO, Schmidt F, Holl RW; DPV Initiative of the German Working Group for Pediatric Diabetology Germany. Impact of physical activity on cardiovascular risk factors in children with type 1 diabetes: a multicenter study of 23,251 patients. Diabetes Care. 2007;30:2098-100.

22. Margeirsdottir HD, Larsen JR, Brunborg C, Overby NC, DahlJørgensen K; Norwegian Study Group for Childhood Diabetes. High prevalence of cardiovascular risk factors in children and adolescents with type 1 diabetes: a population-based study. Diabetologia. 2008;51:554-61.

23. Valerio G, Spagnuolo MI, Lombardi F, Spadaro R, Siano M, Franzese A. Physical activity and sports participation in children and adolescents with type 1 diabetes mellitus. Nutr Metab Cardiovasc Dis. $2007 ; 17: 376-82$.

24. Majaliwa ES, Munubhi E, Ramaiya K, Mpembeni R, Sanyiwa A, Mohn $A$, et al. Survey on acute and chronic complications in children and adolescents with type 1 diabetes at Muhimbili National Hospital in Dar es Salaam, Tanzania. Diabetes Care. 2007;30:2187-92.

25. Sellers EA, Yung G, Dean HJ. Dyslipidemia and other cardiovascular risk factors in a Canadian First Nation pediatric population with type 2 diabetes mellitus. Pediatr Diabetes. 2007;8:384-90.

26. McGill HC Jr, McMahan AC, Malcom GT, Oalmann MC, Strong JP. Relation of glycohemoglobin and adiposity to atherosclerosis in youth. Pathobiological Determinants of Atherosclerosis in Youth (PDAY) Research Group. Arterioscler Thromb Vasc Biol. $1995 ; 15: 431-40$

27. McGill HC Jr, McMahan CA, Herderick EE, Malcom GT, Tracy RE, Strong JP. Origin of atherosclerosis in childhood and adolescence. Am J Clin Nutr. 2000;72:1307S-15S.

28. Bhatt DL, Steg PG, Ohman EM, Hirsch AT, Ikeda Y, Mas JL, et al. International prevalence, recognition, and treatment of cardiovascular risk factors in outpatients with atherothrombosis. JAMA. 2006;295:180-9.

29. Grundy SM, Becker D, Clark LT, Cooper RS, Denke MA, Howard J, et al. Third report of the National Cholesterol Education Program (NCEP) expert panel on detection, evaluation, and treatment of high blood cholesterol in adults (Adult Treatment Panel III) final report. National Institutes of Health. National Heart, Lung, and Blood Institute. NIH Publication, 2002.

30. Hancox RJ, Milne BJ, Poulton R. Association between child and adolescent television viewing and adult health: a longitudinal birth cohort study. Lancet. 2004;364:257-62.

31. Ribeiro RQ, Lotufo PA, Lamounier JA, Oliveira RG, Soares JF, Botter DA. Fatores adicionais de risco cardiovascular associados ao excesso de peso em crianças e adolescentes. O Estudo do Coração de Belo Horizonte. Arq Bras Cardiol. 2006;86:408-18.

32. Yusuf S, Hawken S, Ounpuu S, Dans T, Avezum A, Lanas F, et al. Effect of potentially modifiable risk factors associated with myocardial infarction in 52 countries (the INTERHEART study): case-control study. Lancet. 2004;364:937-52.

33. American Diabetes Association. Standards of medical care in diabetes - 2008. Diabetes Care. 2008;31:S12-54.

34. Haskell WL, Lee IM, Pate RR, Powell KE, Blair SN, Franklin BA, et al. Physical activity and public health: updated recommendation for adults from the American College of Sports Medicine and the American Heart Association. Med Sci Sports Exerc. 2007;39:1423-34.

35. Kohrt WM, Bloomfield SA, Little KD, Nelson ME, Yingling VR. American College of Sports Medicine. American College of Sports Medicine Position Stand: physical activity and bone health. Med Sci Sports Exerc. 2004;36:1985-96. 
36. Center for Disease Control. US Department Of Health And Human Services. Physical activity and good nutrition: essential elements to prevent chronic diseases and obesity. Atlanta (GA): National Center for Chronic Disease Prevention and Health Promotion. http://www.cdc.gov/nccdphp/publications/aag/pdf/dnpa.pdf. Access: $21 / 02 / 2008$.

37. Kimm SY, Glynn NW, Kriska AM, Barton BA, Kronsberg SS, Daniels $S R$, et al. Decline in physical activity in black and white girls during adolescence. N Engl J Med. 2002;347:709-15.

38. Twisk JW, Kemper HC, van Mechelen W. Tracking of activity and fitness and the relationship with cardiovascular disease risk factors. Med Sci Sports Exerc. 2000;32:1455-61.

39. Yang X, Telama R, Viikari J, Raitakari OT. Risk of obesity in relation to physical activity tracking from youth to adulthood. Med Sci Sports Exerc. 2006;38:919-25.

40. de Angelis K, da Pureza DY, Flores LJ, Rodrigues B, Melo KF, Schaan BD, et al. Efeitos fisiológicos do treinamento físico em pacientes portadores de diabetes tipo 1. Arq Bras Endocrinol Metabol. 2006;50:1005-13.

41. Guelfi KJ, Jones TW, Fournier PA. The decline in blood glucose levels is less with intermittent high-intensity compared with moderate exercise in individuals with type 1 diabetes. Diabetes Care. $2005 ; 28: 1289-94$

42. Corigliano G, Iazzetta N, Corigliano M, Strollo F. Blood glucose changes in diabetic children and adolescents engaged in most common sports activities. Acta Biomed. 2006;77:26-33.

43. Zinman B, Ruderman N, Campaigne BN, Devlin JT, Schneider SH. American Diabetes Association. Physical activity/exercise and diabetes. Diabetes Care. 2004;27:S13-54.

44. Tsalikian E, Mauras N, Beck RW, Tamborlane WV, Janz KF, Chase $\mathrm{HP}$, et al. Impact of exercise on overnight glycemic control in children with type 1 mellitus. J Pediatr. 2005;147:528-34.

45. Giannini C, Mohn A, Chiarelli F. Physical exercise and diabetes during childhood. Acta Biomed. 2006;77:18-25.

46. Wojtaszewski JF, Hansen BF, Gade J, Kiens B, Markuns JF, Goodyear $\mathrm{LJ}$, et al. Insulin signaling and insulin sensitivity after exercise in human skeletal muscle. Diabetes. 2000;49:325-31.

47. Herbst A, Bachran R, Kapellen T, Holl RW. Effects of regular physical activity on control of glycemia in pediatric patients with type 1 diabetes mellitus. Arch Pediatr Adolesc Med. 2006;160:573-7.

48. Toni S, Reali MF, Barni F, Lenzi L, Festini F. Managing insulin therapy during exercise in type 1 diabetes mellitus. Acta Biomed. $2006 ; 77: 34-40$.

49. Hoffman RP. Practical management of type 1 diabetes mellitus in adolescent patients: challenges and goals. Treat Endocrinol. 2004;3:27-39.

50. Rabasa-Lhoret R, Bourque J, Ducros F, Chiasson JL. Guidelines for premeal insulin dose reduction for postprandial exercise of different intensities and durations in type 1 diabetic subjects treated intensively with a basal-bolus insulin regimen (ultralente-lispro). Diabetes Care. 2001;24:625-30.

51. Grimm JJ, Ybarra J, Berné C, Muchnick S, Golay A. A new table for prevention of hypoglycaemia during physical activity in type 1 diabetic patients. Diabetes Metab. 2004;30:465-70.

52. Chiarelli F, Verrotti A, Catino M, Sabatino G, Pinelli L. Hypoglycaemia in children with type 1 diabetes mellitus. Acta Paediatr Suppl.1999;88:31-4.

53. De Feo P, Di Loreto C, Ranchelli A, Fatone C, Gambelunghe G, Lucidi P, et al. Exercise and diabetes. Acta Biomed. 2006;77:14-7.

54. Gulve EA. Exercise and glycemic control in diabetes: benefits, challenges, and adjustments to pharmacotherapy. Phys Ther. 2008; 88:1297-321.

55. Robertson K, Adolfsson P, Riddell MC, Scheiner G, Hanas R. Exercise in children and adolescents with diabetes. Pediatric Diabetes. 2008;9:65-77.
56. Sociedade Brasileira de Diabetes. Protocolo hiper/hipoglicemias x corrida para atletas com diabetes. http://www.diabetes.org. br/protocolos/protativfis.php. Access: 13/03/2009.

57. Ferriss JB, Webb D, Chaturvedi N, Fuller JH, Idzior-Walus B. EURODIAB Prospective Complications Group. Weight gain is associated with improved glycaemic control but with adverse changes in plasma lipids and blood pressure in Type 1 diabetes. Diabet Med. 2006;23:557-64.

58. Ramalho AC, Soares S. O papel do exercício no tratamento do diabetes melito tipo 1. Arq Bras Endocrinol Metabol. $2008 ; 52: 260-7$

59. Tuominen JA, Karonen SL, Melamies L, Bolli G, Koivisto VA. Exercise-induced hypoglycaemia in IDDM patients treated with a short-acting insulin analogue. Diabetologia. 1995;38:106-11.

60. Tansey MJ, Tsalikian E, Beck RW, Mauras N, Buckingham BA Weinzimer SA, et al. The effects of aerobic exercise on glucose and counterregulatory hormone concentrations in children with type 1 diabetes. Diabetes Care. 2006;29:20-5.

61. Goulet ED, Mélançon MO, Aubertin-Leheudre M, Dionne IJ. Aerobic training improves insulin sensitivity $72-120 \mathrm{~h}$ after the last exercise session in younger but not in older women. Eur J Appl Physiol. 2005;95:146-52.

62. Sociedade Brasileira de Diabetes. Tratamento e acompanhamento do diabetes mellitus: diretrizes da sociedade brasileira de diabetes, 2007. http://www.diabetes.org.br/educacao/livrosonline.php. Access: $23 / 06 / 2008$.

63. Purdon C, Brousson M, Nyveen SL, Miles PD, Halter JB, Vranic M, et al. The roles of insulin and catecholamines in the glucoregulatory response during intense exercise and early recovery in insulindependent diabetic and control subjects. J Clin Endocrinol Metab. $1993 ; 76: 566-73$

64. Marliss EB, Vranic M. Intense execise has unique effects on both insulin release and its roles in glucoregulation: implications for diabetes. Diabetes. 2002;51:S271-83.

65. Bussau VA, Ferreira LD, Jones TW, Fournier PA. The 10-s maximal sprint: a novel approach to counter an exercise-mediated fall in glycemia in individuals with type 1 diabetes. Diabetes Care. 2006;29:601-6.

66. Guelfi KJ, Jones TW, Fournier PA. Intermitent high-intensity exercise does not increase the risk of early postexercise hypoglycemia in individuals with type 1 diabetes. Diabetes Care. $2005 ; 28: 416-8$

67. Guelfi KJ, Ratnam N, Smythe GA, Jones TW, Fournier PA. Effect of intermittent high-intensity compared with continuous moderate exercise on glucose production and utilization in individuals with type 1 diabetes. Am J Physiol Endocrinol Metab. 2007;292: E865-70.

68. Vettor R, Lombardi AM, Fabris R, Pagano C, Cusin I, RohnerJeanrenaud $F$, et al. Lactate infusion in anesthetized rats produces insulin resistance in heart and skeletal muscles. Metabolism. 1997;46:684-90.

69. Miller BF, Fattor JA, Jacobs KA, Horning MA, Navazio F, Lindinger $M I$, et al. Lactate and glucose interactions during rest and exercise in men: effect of exogenous lactate infusion. J Physiol. 2002;544:963-75.

70. Kreisman SH, Halter JB, Vranic M, Marliss EB. Combined infusion of epinephrine and norepinephrine during moderate exercise reproduces the glucoregulatory response of intense exercise. Diabetes. 2003; 52:1347-54

71. Andersen $\mathrm{H}$. Muscular endurance in long-term IDDM patients. Diabetes Care. 1998;21:604-9.

72. Ramalho AC, de Lourdes Lima M, Nunes F, Cambuí Z, Barbosa C, Andrade $A$, et al. The effect of resistance versus aerobic training on metabolic control in patients with type-1 diabetes mellitus. Diabetes Res Clin Pract. 2006;72:271-6. 
73. Ruzic L, Sporis G, Matkovic BR. High volume-low intensity exercise camp and glycemic control in diabetic children. J Paediatr Child Health. 2008;44:122-8.

74. Dorchy H, Poortmans J. Sport and the diabetic child. Sports Med. $1989 ; 7: 248-62$

75. Gallen I. Exercise in Type 1 diabetes. Diabet Med. 2003;20:2-5.

76. Green L, Adeyanju M. Exercise and fitness guidelines for elementary and middle school children. The Elementary School Journal. $1991 ; 91: 437-44$
Correspondence:

Cristiane Petra Miculis

Centro de Estudos no Esporte e Exercício, Departamento de Educação Física

Universidade Federal do Paraná

Rua Coração de Maria, 92

BR 116, Km 95 - Curitiba, PR - Brazil

Tel.: + 55 (41) 3360.4336

Fax: +55 (41) 3360.4336

E-mail: crispetra@uol.com.br 